Gut, 1986, 27, 86-91

\title{
Serum autoantibodies, ulcerative colitis and primary sclerosing cholangitis
}

\author{
R W CHAPMAN, M COTTONE, W S SELBY, H A SHEPHERD, \\ SHEILA SHERLOCK, AND D P JEWELL \\ From the Department of Gastroenterology, John Radcliffe Hospital, Headington, Oxford, and Department of \\ Medicine, Royal Free Hospital, London
}

SUMMARY The aetiology of primary sclerosing cholangitis is unknown, but it is closely associated with ulcerative colitis. Serum anticolon antibodies, crossreacting with portal tracts, have been reported in patients with ulcerative colitis but no studies have been carried out in primary sclerosing cholangitis. The frequency of serum anticolon antibodies and portal tract antibodies have been measured in 24 patients with primary sclerosing cholangitis and ulcerative colitis; 15 patients with primary sclerosing cholangitis without ulcerative colitis; 77 patients without primary sclerosing cholangitis: 25 patients with Crohn's colitis; 10 patients with primary biliary cirrhosis; 22 patients with extrahepatic biliary obstruction and 20 normal controls. Serum anticolon and portal tract antibodies were detected using immunoperoxidase techniques on normal colon and obstructed human liver. Tissue typing was undertaken using a standard microcytotoxicity technique. The frequency of anticolon antibodies was markedly increased in primary sclerosing cholangitis patients with ulcerative colitis $(62.5 \%)$ compared with patients with ulcerative colitis $(17 \%)$ and Crohn's colitis $(16 \%)\left(\chi^{2}=17 \cdot 9 ; \mathrm{p}<0 \cdot 001\right)$. The antibodies were almost entirely of IgG and IgA classes in all groups. Anticolon antibodies were not found in sera from any other group. Sera from eight of 15 patients with primary sclerosing cholangitis, ulcerative colitis and anticolon antibody reacted with portal tracts of human obstructed liver. This reaction was also seen in four of nine patients with ulcerative colitis and primary sclerosing cholangitis and in three of 15 patients with primary sclerosing cholangitis alone. Portal tract antibody was of IgG class and was not present in sera from any other groups. Unlike anticolon antibody, there was a close relationship between HLA-B8 phenotype and the portal tract antibody $\left(p<0 \cdot 02 ; \chi^{2}=6 \cdot 04\right)$. Absorption studies confirmed that the anticolon antibody is distinct from portal tract antibody.

The aetiology of primary sclerosing cholangitis is unknown, but it is closely associated with ulcerative colitis. ${ }^{1}$ Recent studies have shown that at least $3-4 \%$ of all patients with ulcerative colitis have primary sclerosing cholangitis, ${ }^{23}$ and that approximately two-thirds of patients with primary sclerosing cholangitis have co-existing colitis. ${ }^{14}$ The reason for this close association remains unclear.

Serum anticolon antibodies have been reported in some patients with ulcerative colitis. ${ }^{5}$ The same antibodies have been reported to cross react with proliferating bile ductules from obstructed liver. ${ }^{6}$ The frequency of anticolon antibodies has not been studied previously in patients with primary scleros-

Address for correspondence: Dr D P Jewell, Gastroenterology Unit, Radcliffe Infirmary, Oxford OX2 6HE.

Received for publication 19 April 1985 ing cholangitis, despite accumulating evidence that immunological mechanisms may play an important role in the pathogenesis of primary sclerosing cholangitis. $^{7-9}$

The aims of the present study were firstly to investigate the prevalence of serum anticolon antibodies in patients with ulcerative colitis and primary sclerosing cholangitis, secondly to investigate the relationship between the presence of anticolon antibodies and HLA status, and finally to investigate the cross reaction of anticolon antibodies with proliferating bile ducts.

\section{Methods}

PATIENTS

Sera was obtained from 39 patients with primary 
sclerosing cholangitis (28 men, 11 women). The diagnosis was based on accepted criteria - namely, the demonstration of multiple strictures in the biliary system, the absence of previous biliary tract surgery, and the exclusion of bile duct cancer by at least two years of follow up. ${ }^{4}$ Twenty four patients (17 men, seven women) were also suffering from ulcerative colitis.

Sera was also examined from 77 patients with ulcerative colitis (44 men, 33 women), 25 patients with Crohn's disease (14 men, 11 women), and 20 normal volunteers, (12 men, eight women). All patients included in these groups had normal liver function tests. In addition, sera from 10 patients with primary biliary cirrhosis (one man, nine women) and from 22 patients with extrahepatic cholestasis caused by gall stones, cholangiocarcinoma, or pancreatic carcinoma (13 men, nine women) were tested as a liver disease control group.

Specimens of sera were stored at $-20^{\circ} \mathrm{C}$ until subsequent immunological testing. All patients and control sera were examined at least twice on different occasions.

\section{TISSUES}

One centimetre blocks of normal human colon and obstructed human liver were snap frozen within two hours of surgical resection or biopsy and stored at $-70^{\circ} \mathrm{C}$ until use. Samples of normal or cirrhotic human liver were obtained at necropsy within 12 hours of death and similarly frozen and stored. Samples of gall bladder and cystic duct were obtained from patients operated on for cholecystolithiasis.

\section{ANTISERA}

Rabbit antihuman immunoglobulins $\operatorname{IgA}, \mathrm{G}$, and $\mathrm{M}$, conjugated with peroxidase, were obtained from Dako Laboratories.

\section{IMMUNOCHEMISTRY TECHNIQUES}

Cryostat sections $(6 \mu \mathrm{m})$ were cut at $-20^{\circ} \mathrm{C}$ and fixed in $95 \%$ ethanol for 10 minutes at $4^{\circ} \mathrm{C}$. The sections were mounted at room temperature. The colonic sections were covered with a drop of undiluted patient serum and the liver sections with a drop of patient serum diluted 1 in 10 with phosphate buffered saline (PBS pH 7.2) and placed in a moist chamber for 30 minutes. The sections were then washed with PBS for 10 minutes and stained using an immunoperoxidase method.

IMMUNOPEROXIDASE TECHNIQUE

After the application of serum for 30 minutes, a drop of 1 in 5 diluted normal swine serum was added for 10 minutes and then peroxidase labelled rabbit antihuman immunoglobulins (diluted 1 in 20 with PBS, and further diluted 1 in 20 with swine serum to give a final of 1 in 400) were added for 30 minutes. After a further wash in PBS sections were developed in DAB (3,3'-diaminobenzidine hydrochloride) and mounted in DPX.

\section{MICROSCOPY}

All sections were examined using light microscopy by two experienced observers who were unaware of the patients' diagnosis.

\section{HLA TYPING}

Tissue typing for HLA-A, and B, antigens was carried out by means of a standardised microcytotoxicity assay. ${ }^{10}$

\section{Results}

The frequencies of anticolon antibodies in the groups of sera are shown in Table 1; Figure 1 illustrates the anticolon antibody using immunoperoxidase. In primary sclerosing cholangitis patients with ulcerative colitis there was a significant increase in the frequency of anticolon antibodies $(62.5 \%)$ compared with ulcerative colitis patients $(17 \%)$, and Crohn's disease $(16 \%) \quad\left(\chi^{2}=18 \cdot 1\right.$; $\mathrm{p}<0.001)$. Anticolon antibodies were not detected in primary sclerosing cholangitis patients without ulcerative colitis, patients with primary biliary cirrhosis, patients with extrahepatic cholestasis, nor in normal controls.

In all groups tested, the anticolon antibodies were mainly of IgG and IgA classes (Table 2). There was no difference in the distribution of immunoglobulin subclasses between ulcerative colitis patients with or without primary sclerosing cholangitis.

The HLA-B8 phenotype was found in 7/13 (54\%) of primary sclerosing cholangitis patients with ulcerative colitis possessing a serum anticolon antibody and in six of nine $(67 \%)$ of patients without anticolon antibody.

\section{Table 1 Frequency of anticolon antibodies}

\begin{tabular}{|c|c|c|}
\hline Patients & $\begin{array}{l}\text { Anticc } \\
\text { (no) }\end{array}$ & $\underset{\%}{o d y}$ positive \\
\hline \multirow{2}{*}{$\begin{array}{l}\text { Ulcerative colitis (UC) } \\
\text { UC with primary sclerosing } \\
\text { cholangitis }\end{array}$} & $13 / 77$ & $17 \%$ \\
\hline & $15 / 24$ & $62 \cdot 5 \%$ \\
\hline Crohn's disease & $4 / 25$ & $16 \%$ \\
\hline \multicolumn{3}{|l|}{ Primary sclerosing cholangitis } \\
\hline Normal controls & $0 / 20$ & $0 \%$ \\
\hline Primary biliary cirrhosis & $0 / 10$ & $0 \%$ \\
\hline Extra-hepatic obstruction & $0 / 22$ & $0 \%$ \\
\hline
\end{tabular}




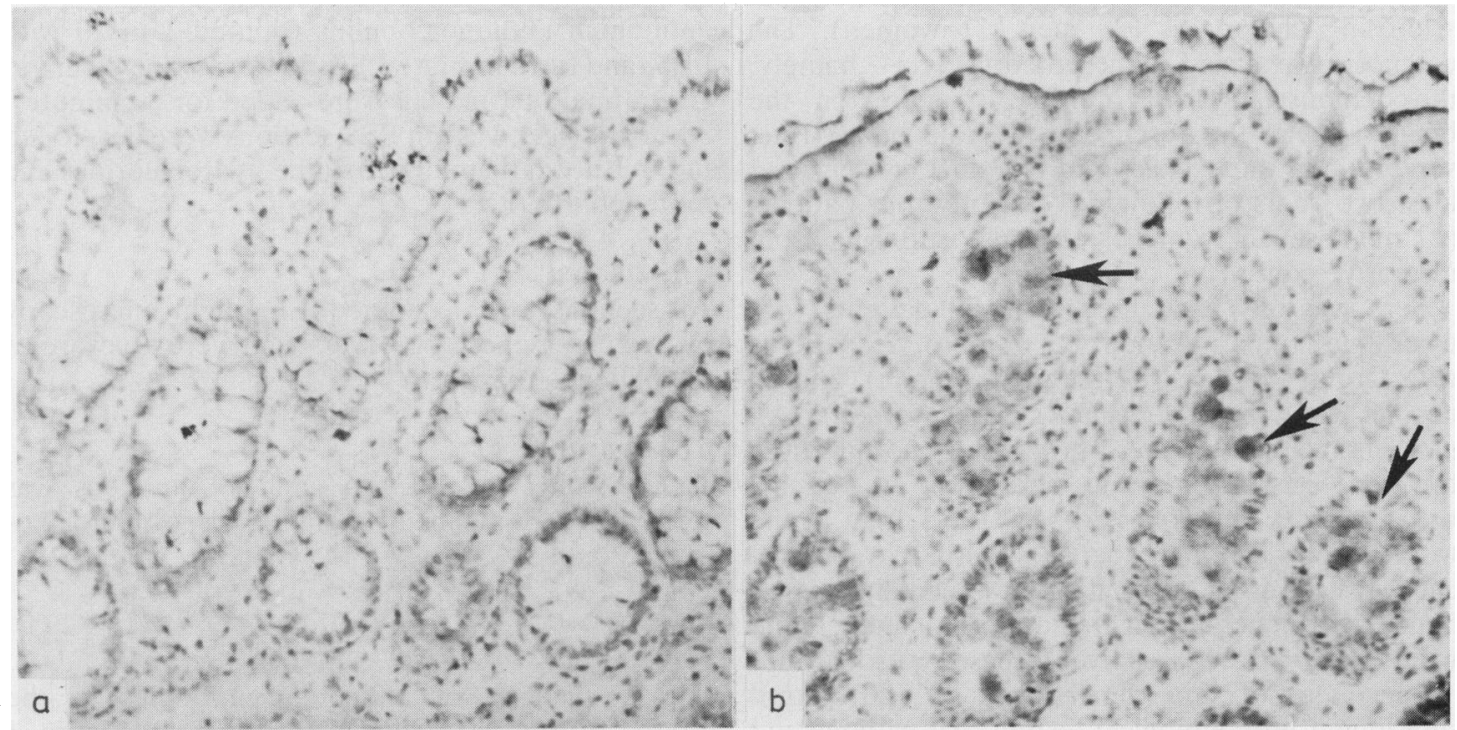

Fig. 1 Immunoperoxidase staining of a cryostat section of human rectal mucosa showing (a) negative reaction; (b) strongly positive reaction involving every crypt (arrows).

The results using liver tissue showed that serum from eight of 15 patients with ulcerative colitis primary sclerosing cholangitis and antiocolon antibody reacted with portal tracts of human obstructed liver. This was also seen in four of nine patients with ulcerative colitis and primary sclerosing cholangitis without anticolon antibody, in two of 25 patients with ulcerative colitis without primary sclerosing cholangitis (one of these was positive for anticolon antibody) and in three of 15 patients with primary sclerosing cholangitis alone. Portal tract antibody was of IgG class in all except one patient who had an IgA antibody. No antibody to portal tracts was present in sera from patients with Crohn's disease, primary biliary cirrhosis, extrahepatic cholestasis, nor in sera from healthy subjects. The portal tract staining was only demonstrable using sections from obstructed human liver and was not seen using sections from normal liver, histologically normal liver from patients with ulcerative colitis without

Table 2 Immunoglobulin subclasses of anticolon antibodies

\begin{tabular}{llll}
\hline Patients & $I g G$ & $I g A$ & $I g M$ \\
\hline $\begin{array}{l}\text { Ulcerative colitis with primary } \\
\text { sclerosing cholangitis } \\
(\mathrm{n}=15)\end{array}$ & $13(87 \%)$ & $8(54 \%)$ & $2(15 \%)$ \\
$\begin{array}{l}\text { Ulcerative colitis } \\
(\mathrm{n}=13)\end{array}$ & $9(70 \%)$ & $7(54 \%)$ & $2(16 \%)$ \\
\hline
\end{tabular}

primary sclerosing cholangitis nor liver from patients with primary biliary cirrhosis. No staining was seen using sections of gall bladder or cystic duct.

In obstructed liver sections positive staining was scattered through the portal tract (Fig. 2). Its relationship to proliferating bile ducts could not be precisely determined, but in some sections, the staining pattern was more obviously ductular (Fig. 2). Unlike the anticolon antibody, there was a close relationship between the presence of HLA-B8 and portal tract staining. Ten of 12 patients with ulcerative colitis and primary sclerosing cholangitis who had circulating portal tract antibodies were also HLA-B8 positive. In contrast only three of 12 such patients without portal tract staining were HLA-B8 positive ( $<<0.02 ; \chi^{2}=6.04$, with Yates correction). All three patients with primary sclerosing cholangitis alone and portal tract staining were HLA-B8 positive.

Absorption studies were undertaken on sera from two patients with high titres of anticolon and portal tract antibodies. Anticolon antibody could be absorbed by incubating patients' sera with homogenised rectal biopsies from normal human colon (patients with irritable bowel syndrome). Portal staining could not, however, be absorbed with colonic tissue. Similarly, absorption with obstructed liver homogenate abolished portal tract staining but did not affect staining on colonic tissue confirming that two distinct antibodies were present. Neither portal tract or colonic staining could be absorbed 


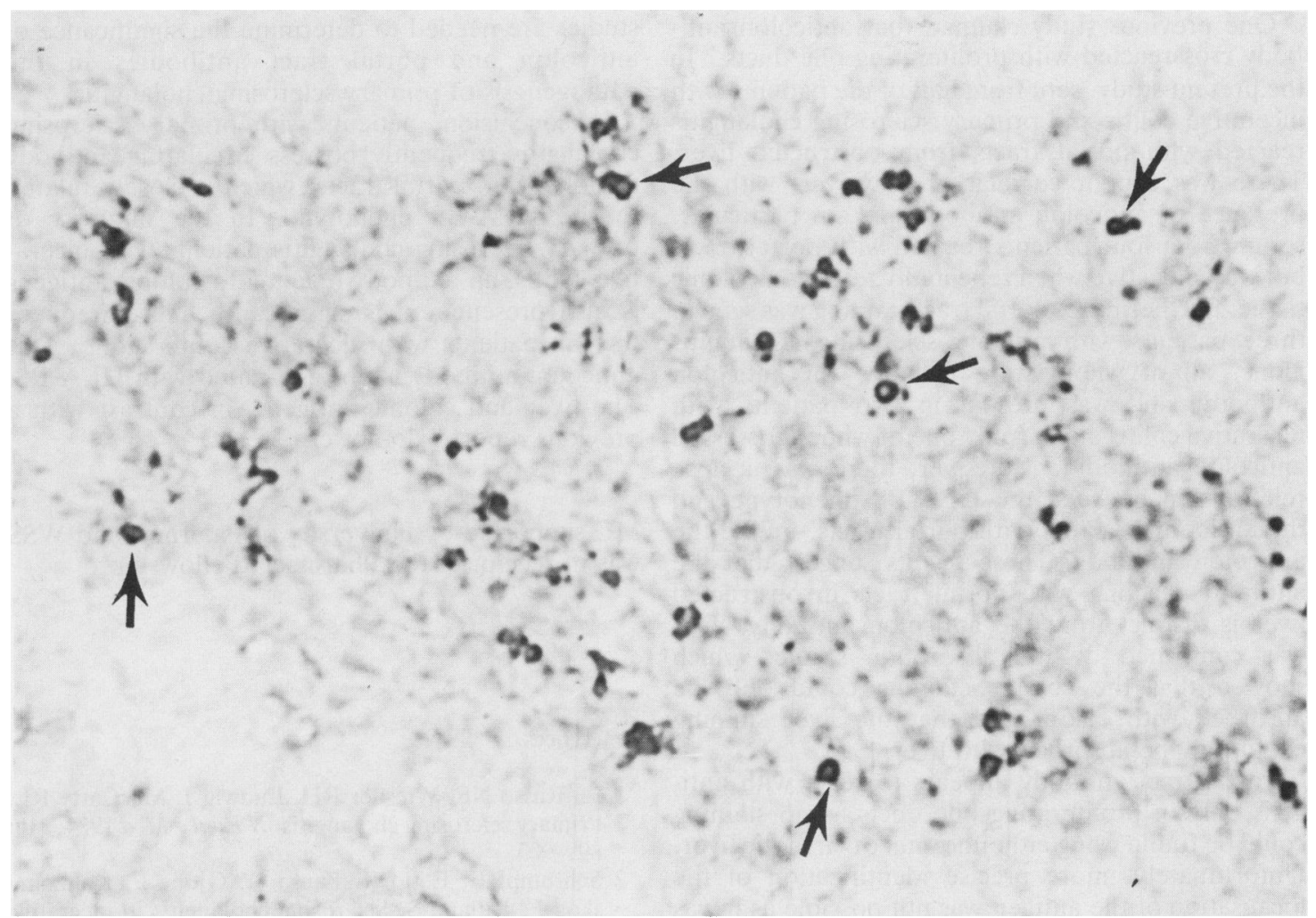

Fig. 2 Immunoperoxidase staining of a cryostat section of human obstructed liver showing a strongly positive portal tract reaction.

using homogenates of normal human liver.

\section{Discussion}

This study has shown that about $17 \%$ of patients with ulcerative colitis possess a circulating antibody to a colonic antigen. This frequency is similar to that reported previously using indirect immunofluorescence techniques. ${ }^{11}{ }^{12}$ Antibodies were mainly of IgG or $\operatorname{IgA}$ class, and only $15 \%$ of our patients with anticolon antibodies had an IgM antibody. In contrast, the only other study of immunoglobulin class in patients with ulcerative colitis and anticolon antibodies, found that IgM antibodies predominated. ${ }^{13}$

There was a markedly increased frequency of circulating anticolon antibody in patients with primary sclerosing cholangitis in association with ulcerative colitis compared with patients with ulcerative colitis alone. Furthermore, anticolon antibodies were not found in patients with primary sclerosing cholangitis alone, in patients with primary biliary cirrhosis, nor in healthy control subjects. Despite the fact that $60 \%$ of the patients with primary sclerosing cholangitis and ulcerative colitis possessed the HLA-B8 phenotype, there was no correlation between HLA status and presence of anticolon antibodies.

Although the majority of patients with primary sclerosing cholangitis had extensive, mild colitis, ${ }^{3}$ the high frequency of anticolon antibodies is unlikely to be related to this, as no association has been found between anticolon antibodies and any of the clinical variables of ulcerative colitis. ${ }^{11}$

Triger $e t$ al, ${ }^{14}$ have reported a higher frequency of anticolon antibodies in the sera of patients with chronic liver disease $(25 \%)$ compared with control subjects, using a haemagglutination technique. They suggested that this may be because of failure to clear antigen from portal blood. Using immunoperoxidase techniques, however, this study has shown that anticolon antibodies were not present in patients with primary biliary cirrhosis or with primary sclerosing cholangitis alone. Therefore, the high frequency found in patients with primary sclerosing cholangitis and ulcerative colitis appears specific. 
One previous study claimed that anticolon antibody crossreacted with proliferating bile ducts. ${ }^{6}$ In the present study, sera from half of the patients with ulcerative colitis and primary sclerosing cholangitis reacted with portal tracts from obstructed liver. There was a poor correlation, however, with the presence of anticolon antibody and, in particular, serum from four patients reacted with portal tracts but were negative when repeatedly tested on colonic tissue. Furthermore, portal tract staining was seen in three patients with primary sclerosing cholangitis alone, all of whom were negative for anticolon antibody, and was present in two patients with ulcerative colitis alone (only one of whom possessed anticolon antibody). Moreover, there was a close relationship between the HLA-B8 phenotype and the antibody reacting with portal tracts, unlike the anticolon antibody. These results suggest that the antibody reacting with portal tracts in obstructed liver is distinct from the anticolon antibody. This was confirmed by the absorption studies which showed that the colonic staining could only be absorbed with colon, and that the liver staining could only be absorbed with liver.

Portal tract antibody appears to react with antigens only in proliferating bile ducts as no staining could be found using either normal or cirrhotic liver. Unfortunately, more precise identification of the localisation of the antigen was not possible as it was destroyed by fixation for electron microscopy (unpublished observations).

McFarlane $e t a l^{7}$ have shown that lymphocytes of patients with primary sclerosing cholangitis are sensitised to a biliary antigen using a leucocyte migration inhibition test. Patients with primary biliary cirrhosis and chronic active hepatitis, however, may also show this hypersensitivity. Therefore it seems unlikely that the antigen involved is the same as that reacting with the portal tract antibodies found in the sera of our patients with primary sclerosing cholangitis, as the antibodies were not found in patients with primary biliary cirrhosis.

There is increasing evidence that immunological mechanisms may play an important role on the pathogenesis of primary sclerosing cholangitis. $^{781516}$ We have described previously ${ }^{39}$ and confirmed in this study that there is an increased prevalence of HLA-B8 in primary sclerosing cholangitis patients with and without ulcerative colitis. The presence of HLA-B8 has been associated with a number of organ specific autoimmune diseases such as Type I diabetes mellitus, 'lupoid' chronic active hepatitis, myasthenia gravis, and thyrotoxicosis. ${ }^{17}$ These diseases are characterised by the production of autoantibodies which in some cases probably play an important role in pathogenesis. ${ }^{18} 19$ Further studies are needed to determine the significance of anticolon and portal tract antibodies in the pathogenesis of primary sclerosing cholangitis.

In conclusion, patients with primary sclerosing cholangitis frequently possess circulating antibody to obstructed portal tracts, which is closely related to the HLA-B8 phenotype. In the majority of primary sclerosing cholangitis patients with ulcerative colitis, an antibody reacting to colonic antigens is also present and is significantly more frequent than in patients with ulcerative colitis alone. This anticolon antibody is not associated with HLA-B8. The liver and colonic antigens, in contrast with a previous report, ${ }^{6}$ do not crossreact.

MC supported by University of Palermo, and WSS was in receipt of the Pharmacia Fellowship.

\section{References}

1 La Russo NF, Wiesner RH, Ludwig J, MacCarty RL. Primary sclerosing cholangitis. N Engl J Med 1984; 310: 899-903.

2 Schrumpf E, Elgjo K, Fausa O, Gjone F, Kolmannskog F, Ritland S. Sclerosing cholangitis in ulcerative colitis. ScandJ Gastroenterol 1980; 15: 689-97.

3 Shepherd HA, Selby WS, Chapman RWG et al. Ulcerative colitis and liver dysfunction. $Q J$ Med 1983; 52: 503-13.

4 Chapman RWG, Arborgh BA, Rhodes JM et al. Primary sclerosing cholangitis - review of its clinical features, cholangiography, and hepatic histology. Gut 1980; 21: 870-7.

5 Broberger O, Perlmann P. Antibodies in human ulcerative colitis. J Exp Med 1963; 110: 657-74.

6 Koffler D, Minkowitz MD, Rothman W, Garlock J. Immunocytochemical studies in ulcerative colitis and regional ileitis. J Exp Med 1962; 41: 733-41.

7 McFarlane IG, Wojcicka BM, Demetrios C, et al. Leukocyte migration in response to biliary antigens in primary biliary cirrhosis, sclerosing cholangitis, and other chronic liver diseases. Gastroenterology 1979; 76: 1333-40.

8 Bodenheimer HC, LaRusso NF, Thayer WR, et al. Elevated circulating immune complexes in primary sclerosing cholangitis. Hepatology 1983; 3: 150-4.

9 Chapman RW, Varghese Z, Gaul R, Patel G, Kokinon $\mathrm{N}$, Sherlock S. Association of primary sclerosing cholangitis with HLA-B8. Gut 1983; 28: 38-41.

10 Mittal KK, Mickey MR, Singal DP, et al. Serotyping for oro-transplantation XVIII - refinement of microdroplet lymphocytotoxicity test. Transplantation 1968; 6: 313-27.

11 Wright $\mathrm{R}$, Truelove SC. Autoimmune reactions in ulcerative colitis. Gut 1966; 7: 32. 
Serum autoantibodies, ulcerative colitis and primary sclerosing cholangitis

12 Marcussen H, Nerup G. Fluorescent anticolon and organ specific antibodies in ulcerative colitis. Scand $J$ Gastroenterol 1973; 8: 9-15.

13 Zeromski J, Perlman P, Lagercrantz R, Hammerstrom S, Gustafsoon F. Immunological studies in ulcerative colitis. VII. Anticolon antibodies of different immunoglobulin classes. Clin Exp Immunol 1970; 7: 468-75.

14 Triger DR, Alp MH, Wright R. Bacterial and dietary antibodies in liver disease. Lancet 1972; 1: 60-3.

15 Brinch L, Teisberg P, Schrumpf E, Akesson I. The in vivo metabolism of $\mathrm{C} 3$ in hepatobiliary disease associated with ulcerative colitis. Scand J Gastroenterol 1982; 17: 523-7.
16 Alberti-Flor JJ, Medina M de, Jeffers L, Schiff ER. Elevated immunoglobulins and immune complexes in the bile of patients with primary sclerosing cholangitis. Hepatology 1984; 3: 844.

17 Eddleston ALWF, Williams R. HLA and liver disease. Br Med Bull 1978; 34: 295-300.

18 Doberson MJ, Scharff JE, Ginsberg-Fellner F, Notkins AL. Cytotoxic autoantibodies to beta cells in the serum of patients with insulin-dependent diabetes mellitus. $N$ Engl J Med 1980; 305: 1493-8.

19 DeAizpura HJ, Cosgrove LJ, Ungar B, Toh B-H. Autoantibodies cytotoxic to gastric parietal cells in serum of patients with pernicious anaema. $N$ Engl $J$ Med 1983; 309: 625-9. 